Bull. Chem. Soc. Ethiop. 2017, 31(2), 281-289.

ISSN 1011-3924

(C) 2017 Chemical Society of Ethiopia and The Authors

Printed in Ethiopia

DOI: http://dx.doi.org/10.4314/bcse.v31i2.9

\title{
DEALUMINATION OF MORDENITE ZEOLITE AND ITS CATALYTIC PERFORMANCE EVALUATION IN $m$-XYLENE ISOMERIZATION REACTION
}

\author{
Zahra Vosoughi Rahbari ${ }^{1 *}$, Mehrji Khosravan ${ }^{1}$, Ali Nemati Kharat ${ }^{2}$ \\ ${ }^{1}$ Department of Chemistry, Faculty of Science, ShahidBahonar University of Kerman, Kerman, \\ Iran \\ ${ }^{2}$ Department of Chemistry, Faculty of Science, University of Tehran, Tehran, Iran
}

(Received November 16, 2016; revised October 11, 2017)

\begin{abstract}
Mordenite zeolite with $\mathrm{Si} / \mathrm{Al}=18$ was successfully synthesized by the hydrothermal method. This zeolite was modified by partially dealuminated in $\mathrm{HNO}_{3}$ at $70{ }^{\circ} \mathrm{C}$. Our analysis showed that the surface area of modified mordenite was increased more than that of the mordenite zeolite. Acid leaching removes impurities and aluminium from the zeolite network, improving $\mathrm{Si} / \mathrm{Al}$ ratio of the framework and increasing the external surface area of the zeolite. The catalytic performances of these synthesized catalysts were investigated for metaxylene isomerization reaction in a fixed bed reactor. The performances were then benchmarked with the performance of SAPO-11, a commercially available catalyst. The results showed that $p$-xylene/o-xylene ratio over the catalysts was found to be in the order: dealuminated mordenite $>$ mordenite $>$ SAPO-11, however dealuminated mordenite and SAPO-11 gave higher $m$-xylene conversion than that of the mordenite.
\end{abstract}

KEY WORDS: Dealuminated mordenite, Catalyst, $m$-Xylene isomerization, SAPO-11

\section{INTRODUCTION}

The $\mathrm{C}_{8}$ aromatic fraction in a refinery consists mainly of four isomers, $o$-xylene, $m$-xylene, $p$ xylene and ethylbenzene [1]. The xylene mixtures result from the catalytic reforming of petroleum NAFTA and the isomers of xylenes are usually obtained from this mixture by separation. After separation of $o$-isomers and $p$-isomers, the remainder richer in $m$-xylene, needs to be subjected to isomerization [2]. Xylene isomerization has received growing attention because of the increased demand of $p$-xylene [3]. Production of $p$-xylene is a petrochemical process of great importance since its oxidation yields terephthalic acid, which is a major component in the production of polyester fibers, synthetic resins, vitamins and pharmaceuticals [4]. Figure 1 shows the mechanism of $m$-xylene isomerization.

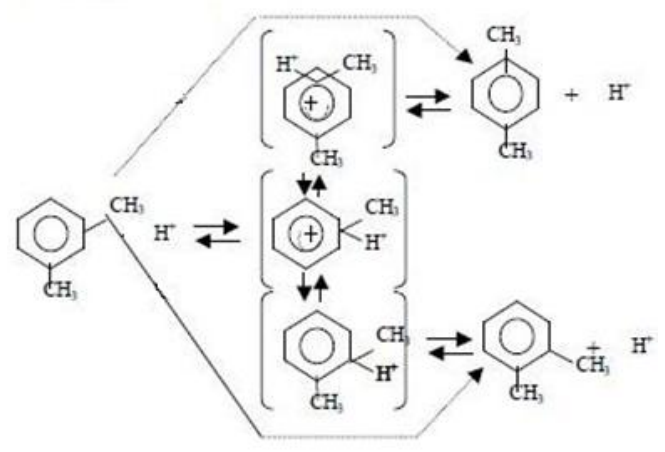

Figure 1. Mechanism of $m$-xylene isomerization [5].

*Corresponding author. E-mail: zahravosoughi@yahoo.com

This work is licensed under the Creative Commons Attribution 4.0 International License 
Zeolites are well known microporous materials that widely used as catalysts in the petrochemical industry because of their large surface area, shape selectivity, and controllable acidity $[6,7]$. The general formula of zeolites is $\mathrm{M}_{\mathrm{x} / \mathrm{n}}\left[\left(\mathrm{AlO}_{2}\right)_{\mathrm{x}} \cdot\left(\mathrm{SiO}_{2}\right)_{\mathrm{y}}\right] \cdot \mathrm{wH}_{2} \mathrm{O} \cdot \mathrm{M}=$ exchange cation of valency, $n, w=$ the number of water molecules, $x+y=$ the total number of tetrahedral per unit cell [8].

Among the various zeolites, mordenite types were found to possess better isomerization activity due to their shape selectivity, high thermal and acid stability $[3,9,10]$. The structure of mordenite determined by Meier in 1961 [11]. The micropore system of mordenite has a onedimensional pore system that consists of two-pore channels, 12-membered oxygen ring channel with pore opening $6.7 \times 7 \AA$ which is interconnected to 8 -membered oxygen ring channel with opening $2.65 .7 \AA[10,12,13]$. It has an orthorhombic crystal structure and 5-membered rings stacked in columns parallel to the [001]-direction framework [14].

Mordenite is an industrially important zeolite and also used as a solid catalyst for many reactions such as alkylation, disproportionation, trans-alkylation, hydrocracking, hydroisomerization, dehydration, steam reforming, polymerization, dewaxing and xylenes isomerization $[8,9]$. It also widely used in separation and purification due to its uniform, small pore size, flexible framework, high internal surface area and controlled chemistry [11].

Dealumination of zeolites is an essential step in the synthesis of a large number of commercial zeolite formulations. Barrer and Makki demonstrated that a natural zeolite clinoptilolite can be dealuminated by treatment with hydrochloric acid without loss of the zeolite structure [15]. Mild acid dealumination of H-MOR was reported to result in a more active catalyst [16]; due to the removal of amorphous material from the structure channels, as well as the generation of stronger acid sites during the dealumination process [17].

In general, mordenite catalysts undergo rapid deactivation because of their uni-dimensional pore system with small side-pockets that are generally not accessible for reactant molecules, and limit the free diffusion of intermediate and product molecules. However, by applying dealumination methods, mordenite has been successfully used in industrial processes such as isomerization and hydro isomerization of hydrocarbons $[18,19]$.

In this study, we prepared the mordenite and modified it by leaching with nitric acid, then studied some properties of framework such as $\mathrm{Si} / \mathrm{Al}$ ratio, pore volume and surface area. At final, investigated the catalytic performance of synthesized mordenite and dealuminated mordenite in $m$-xylene isomerization and compared to commercial SAPO-11.

\section{EXPERIMENTAL}

\section{Materials}

$\mathrm{SiO}_{2}$ as a silica source, sodium aluminate as an alumina source and sodium hydroxide, all of them were purchased from Sigma-Aldrich (USA). Nitric acid for modifying the zeolite was purchased from Merck. Crystallization was carried out in a Teflon coated stainless steel autoclave in a conventional oven.

\section{Synthesis of catalyst}

Mordenite zeolite was prepared using the procedures as described in the literature [11]. This reaction contains the follow steps: (1) $4.75 \mathrm{~g} \mathrm{NaOH}$ was dissolved in $10 \mathrm{~mL}$ the water, (2) 3.75 g sodium aluminate was added to this solution and the mixture was stirred until dissolution, (3) $161.25 \mathrm{~mL}$ water was added to this solution, and (4) finally, $24.55 \mathrm{~g} \mathrm{SiO}_{2}$ was added and the mixture was stirred for 2 days. The molar composition of the prepared gel was: $6 \mathrm{Na}_{2} \mathrm{O}: \mathrm{Al}_{2} \mathrm{O}_{3}: 30 \mathrm{SiO}_{2}: 780 \mathrm{H}_{2} \mathrm{O}$. 
The resulted gel was transferred to a reactor made of stainless steel coated with Teflon and heated to $180{ }^{\circ} \mathrm{C}$ for 24 hours in a conventional oven for crystallization of the compound. The precipitate was filtered off and washed with water, then using concentrated sulfuric acid the $\mathrm{pH}$ of the filtrate was adjusted to about 9 . The obtained solid was dried at $110^{\circ} \mathrm{C}$.

Acid leaching

Nitric acid (70\% pure, Merck) was used as dealuminating agent. The mordenite zeolite underwent 3 successive acid attacks using $2 \mathrm{M}$ nitric acid at about $70{ }^{\circ} \mathrm{C}$ for 4 hours. The volume $\mathrm{V}$ of the nitric acid solution used (in $\mathrm{mL}$ ) was equal to 10 times the weight $\mathrm{P}$ (in grams) of dry mordenite zeolite $(\mathrm{V} / \mathrm{P}=10)$. Between each of the acid attacks, the zeolite was washed with water. Next, the zeolite was dried overnight at $100{ }^{\circ} \mathrm{C}$.

\section{Catalyst characterization}

X-Ray powder diffraction patterns were recorded on an PHILIPS PW1800 instrument using $\mathrm{CuK}_{\alpha}$ radiation. XRD patterns recorded from 4 to $54^{\circ}(2 \theta)$. The $\mathrm{SiO}_{2} / \mathrm{Al}_{2} \mathrm{O}_{3}$ ratio was determined by the PHILIPS PW1480 X-ray Fluorescence Spectrometer. The surface area and pore volume of the samplewere calculated using BET (JWGB K132F) equation. SEM (VEGA \TESCAN) was used for determination of the crystal size of mordenite with an acceleration voltage of 15.00 $\mathrm{kV}$. The lattice vibration in the inorganic framework was determined with FT-IR (BomemMB).

\section{Catalyst activity measurements}

$m$-Xylene isomerization was carried out in a fixed bed reactor according to the following conditions: pressure: 10 bar, temperature: $380^{\circ} \mathrm{C}$, the amount of catalyst: ca. $4 \mathrm{~g}$ of H-mordenite catalyst (6-10 mm mesh), space velocity (WHSV) of feed: $3.35 \mathrm{~h}^{-1}$, catalyst depth: $1.2 \mathrm{~mm}$. The hydrogen gas co-feed into the reactor for hydrogenation of ethylbenzene in order to the hydrogenation products convert ethylbenzene to xylenes [20].

The catalyst was placed in the center of a stainless steel reactor and heated by a furnace. The composition of the feedstock is shown in Table 1.

Table 1. Composition of the feedstock ( $w t \%)$.

\begin{tabular}{|c|c|c|c|c|c|}
\hline PX & MX & OX & EB & T & B \\
\hline 3.282 & 51.452 & 24.151 & 12.004 & 0.881 & 0.00 \\
\hline
\end{tabular}

Notes: PX: p-xylene, MX: $m$-xylene, OX: $o$-xylene, EB: ethylbenzene, T: toluene, B: benzene.

The analysis of products was performed using gas chromatograph (Varian 3800) every $8 \mathrm{~h}$. Figure 2 shows the schematic diagram of the experimental setup. $m$-Xylene conversion, $p$ xylene/o-xylene ratio and xylene loss were calculated according to equations 1-3.

$\mathrm{MX}$ conversion $=\frac{\text { mass fraction of MX in feedstock }- \text { mass fraction of MX in products }}{\text { mass fraction of MX in feedstock }} \times 100 \%$

$\mathrm{PX} / \mathrm{OX}=\frac{\text { mass fraction of } \mathrm{PX} \text { in products }}{\text { mass fraction of } \mathrm{OX} \text { in products }} \times 100 \%$

Xylene loss $=\frac{\text { mass fraction of }(\mathrm{OX}+\mathrm{MX}+\mathrm{PX}) \text { in feedstock-mass fraction of }(\mathrm{OX}+\mathrm{MX}+\mathrm{PX}) \text { in products }}{\text { mass fraction of }(\mathrm{OX}+\mathrm{MX}+\mathrm{PX}) \text { in feedstock }} \times 100 \%$

(Mass fraction is based on $\mathrm{wt} \%$ ) 


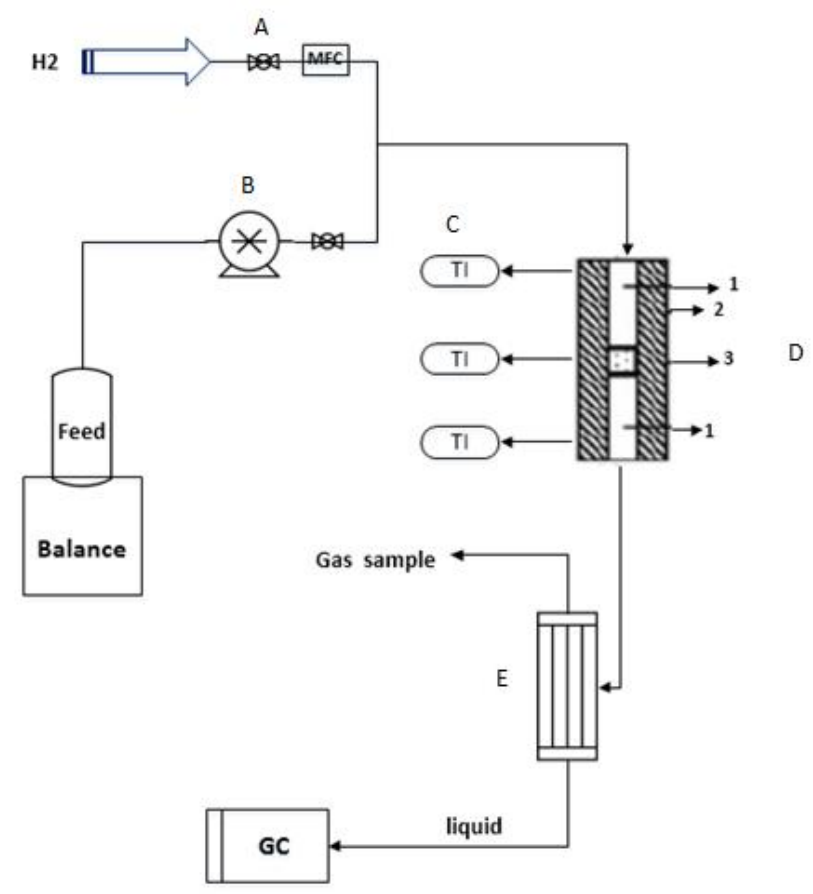

Figure 2. Schematic diagram of the experimental setup for $m$-xylene isomerization (A) ball value, (B) HPLC pump, (C) temperature indicator, (D) isothermal reactor, (E) condenser, (1) quartz, (2) wool, (3) catalyst.

\section{RESULTS AND DISCUSSION}

\section{$X$-ray diffraction studies}

Figure 3 shows the X-ray pattern of synthesized mordenite. The intense diffraction peaks were between $4^{\circ}$ and $54^{\circ}(2 \theta)$. These diffraction peaks are corresponding to the main zeolite $[10,21,22]$ and exhibited that a highly crystalline and pure sample has been formed. The XRD pattern of the dealuminated zeolites with acid treatementis essentially identical to those of the corresponding parent zeolites [23].

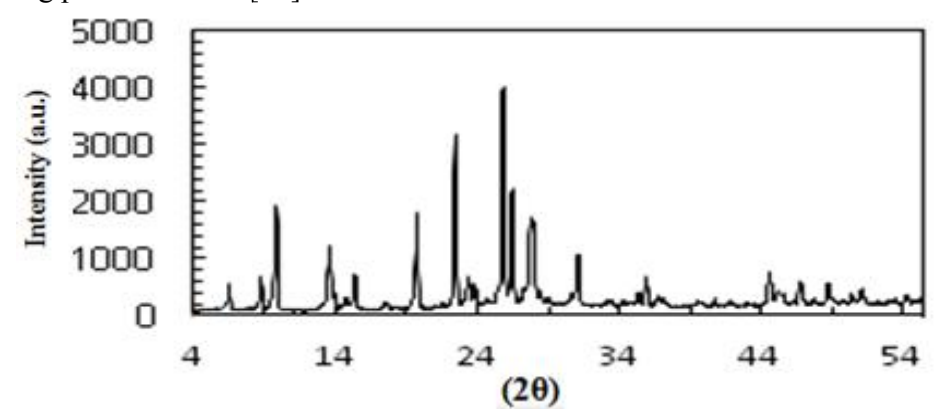

Figure 3. XRD pattern of the synthesized mordenite. 
Surface area

Some properties of both of the synthesized samples are given in Table 2. Indications of structural changes are evidenced from the surface area and porosity, where both the surface area and pore volume of the parent mordenite were increased after acid leaching. Increase in the pore volume also suggests that the micropore volume of mordenite is increased after acid treatment [12].

Table 2. Properties of the synthesized mordenite and dealuminate dmordenite.

\begin{tabular}{|c|c|c|c|}
\hline Sample & $\underline{\mathrm{Si} / \mathrm{Al}}$ & BET surface area $\left(\mathrm{m}^{2} / \mathrm{g}\right)$ & Pore volume $\left(\mathrm{m}^{3} / \mathrm{g}\right)$ \\
\hline & $\mathrm{XRF}$ & & \\
\hline Mordenite & 18 & 331.63 & 0.278 \\
\hline Dealuminated mordenite & 30 & 354.65 & 0.281 \\
\hline
\end{tabular}

\section{SEM studies}

Figure 4 shows that the morphology and size of the synthesized mordenite are similar with other studies as reported already $[10,21,24]$. Electron microscopy shows that synthesized mordenite has the crystal size about 5-7 $\mu \mathrm{m}$.

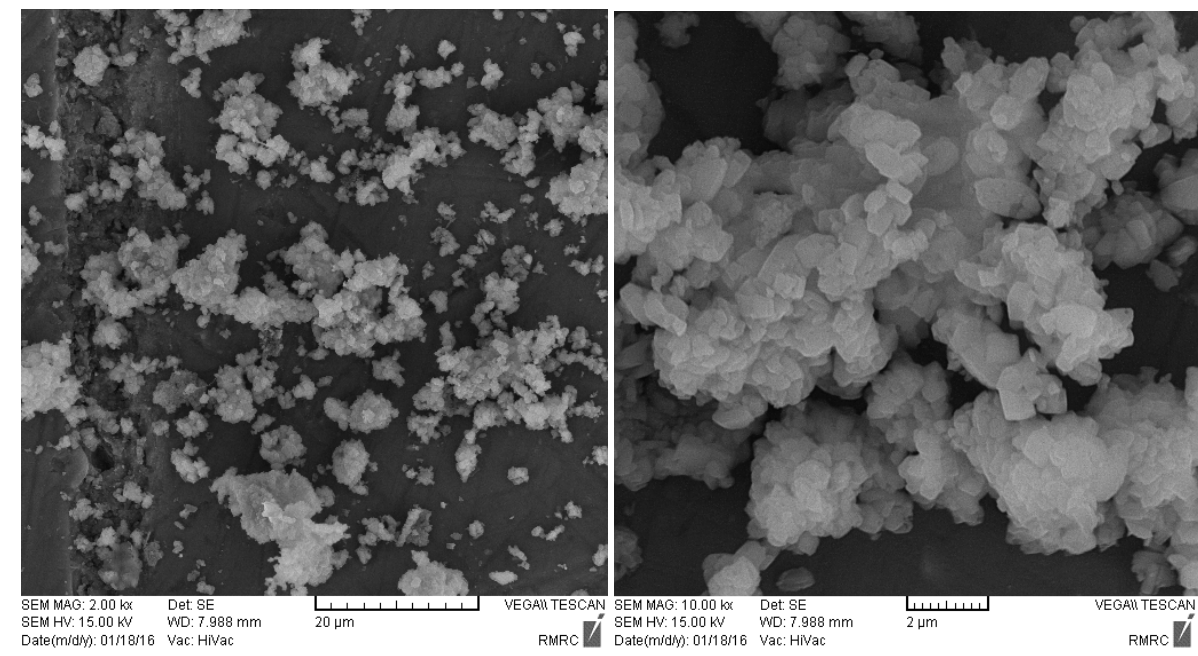

Figure 4. SEM images of the synthesized mordenite.

FT-IR studies

Figure 5 shows FT-IR spectra of Na-mordenite. It has some main absorption regions, the peak around to $1083 \mathrm{~cm}^{-1}$ ascribed to the stretch $\gamma$ of Si-O bond and another peak near to $810 \mathrm{~cm}^{-1}$ referring to symmetric stretch $\gamma$ of Al-O bond. It also has a peak at $638 \mathrm{~cm}^{-1}$ belonging to $\mathrm{SiO}_{4}$ and $\mathrm{AlO}_{4}$ tetrahedra and a peak centered at $583 \mathrm{~cm}^{-1}$ related to the vibration of five-membered rings $[9,10]$. There was no significant difference with dealuminated mordenite (H-MOR) $[25$, 26]. 


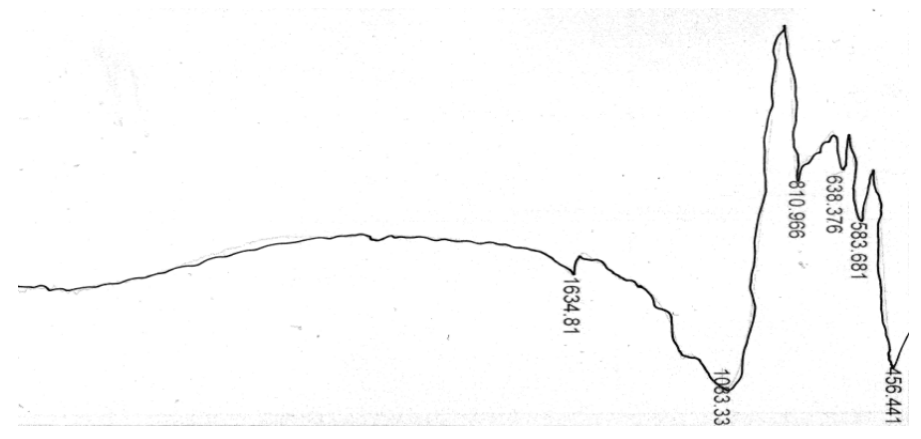

Figure 5. IR spectrum of the synthesized mordenite.

In order to investigate the application of the prepared zeolite in $m$-xylene isomerization reaction, the synthesized mordenite sample and dealuminated mordenite have been tested in a fixed bed catalytic setup and compared the results with a commercial SAPO-11 catalyst $(\mathrm{Si} / \mathrm{Al}=$ 20) provided by Zeolite International.

In Table 3, the results of $m$-xylene conversion to $p$-xylene at a pressure of 10 bar and $380{ }^{\circ} \mathrm{C}$ on three zeolites are shown.

Table 3. Comparison of catalytic activity of prepared mordenite and dealuminated mordenite catalysts with commercial SAPO-11 catalyst.

\begin{tabular}{|l|c|c|c|c|c|c|}
\hline Catalyst & Mordenite & & $\begin{array}{c}\text { Dealuminated } \\
\text { mordenite }\end{array}$ & & $\begin{array}{c}\text { SAPO- } \\
11\end{array}$ & \\
\hline Temp. $\left({ }^{\circ} \mathrm{C}\right)$ & 380 & 380 & 380 & 380 & 380 & 380 \\
\hline Catalyst $(\mathrm{g})$ & 4 & 4 & 4 & 4 & 4 & 4 \\
\hline WHSV $\left(1 \mathrm{~h}^{-1}\right)$ & 3.35 & 3.35 & 3.35 & 3.35 & 3.35 & 3.35 \\
\hline Time $(\mathrm{h})$ & 6 & 12 & 6 & 12 & 6 & 12 \\
\hline$p$-xylene & 13.20 & 10.96 & 14.62 & 12.21 & 10.07 & 8.81 \\
\hline$m$-xylene & 43.78 & 43.97 & 42.34 & 42.86 & 43.01 & 44.19 \\
\hline$o$-xylene & 20.74 & 21.16 & 20.13 & 20.93 & 21.05 & 21.81 \\
\hline Ethylbenzene & 6.63 & 8.40 & 8.94 & 9.95 & 9.86 & 10.35 \\
\hline Toluene & 1.96 & 1.42 & 1.04 & 0.94 & 1.46 & 1.31 \\
\hline Benzene & 0.92 & 0.55 & 0.85 & 0.73 & 0.12 & 0.09 \\
\hline MX conversion $(\%)$ & 14.91 & 14.54 & 17.71 & 16.70 & 16.40 & 14.11 \\
\hline PX/OX $(\%)$ & 63 & 52 & 73 & 58 & 48 & 40 \\
\hline Xylene loss $(\%)$ & 2.11 & 3.54 & 2.39 & 3.78 & 6.03 & 5.16 \\
\hline
\end{tabular}

m-Xylene conversion over the zeolite catalysts

Conversion of $m$-xylene over zeolite catalysts are plotted versus reaction time in Figure 6. With the reaction time of $6 \mathrm{~h}$ over mordenite, $m$-xylene conversion reached a conversion of 14.91 compared to 17.71 over dealuminated mordenite and 16.40 over SAPO-11. Similarly, with the reaction time of $12 \mathrm{~h}$. Figure 6 shows that $m$-xylene conversion reached a conversion of 14.54 , compared to 16.70 over dealuminated mordenite and 14.11 over the SAPO-11.

The results shown in Figure 6, demonstrate that catalyst comprising a dealuminated mordenite zeolite performed much better catalytically in terms of $m$-xylene conversion than that catalyst comprising a non-dealuminated mordenite zeolite and SAPO-11. Such effect was ascribed to the presence of fewer and stronger Brønsted acid sites [27]. 


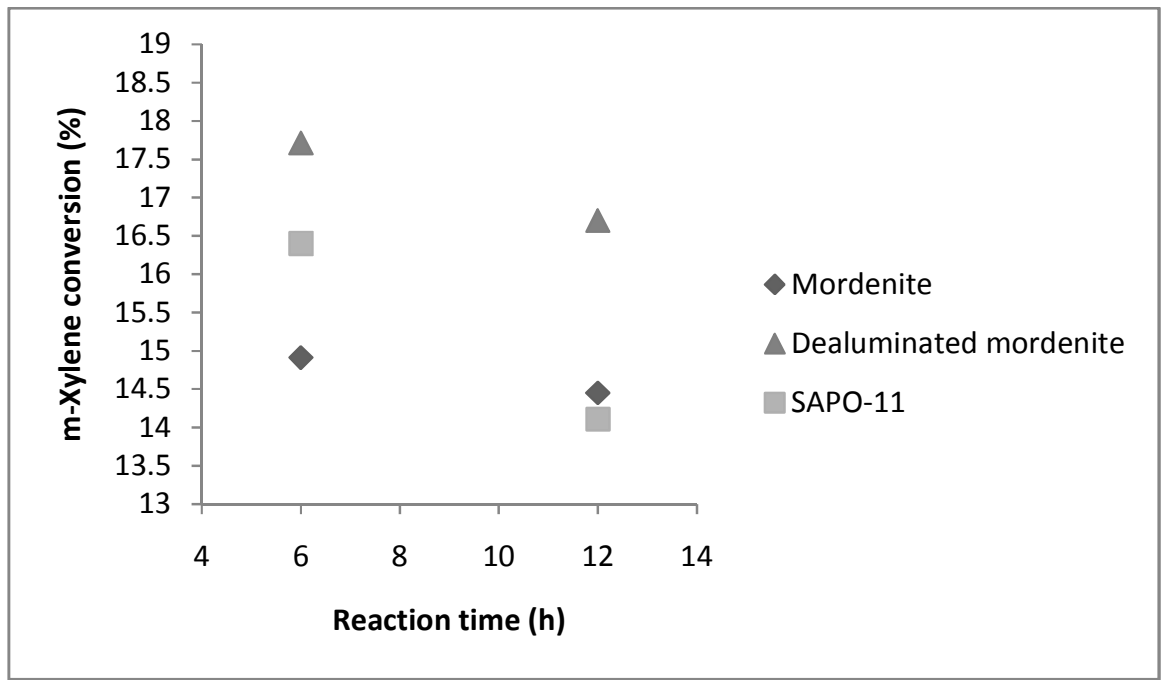

Figure 6. Xylene conversions versus reaction time at $380^{\circ} \mathrm{C}$ over 3 zeolites.

According to the Figure 6, for three catalysts when the reaction time increased from $6 \mathrm{~h}$ to $12 \mathrm{~h}$, the conversion m-xylene was decreased.

p-Xylene to o-xylene $(\mathrm{P} / \mathrm{O})$ ratio

The para to ortho ratio over mordenite, dealuminated mordenite and SAPO-11 are presented in Figure 7 for all three $6 \mathrm{~h}$ and $12 \mathrm{~h}$ reaction times.

As it is depicted in Figure 7, extending the reaction time resulted in a smaller $\mathrm{P} / \mathrm{O}$ ratio for all three catalysts. However, it is worth mentioning that regardless of the reaction time, dealuminated modernite and mordenite catalysts consistently provided higher level of $\mathrm{P} / \mathrm{O}$ ratio as compared to SAPO- 11 .

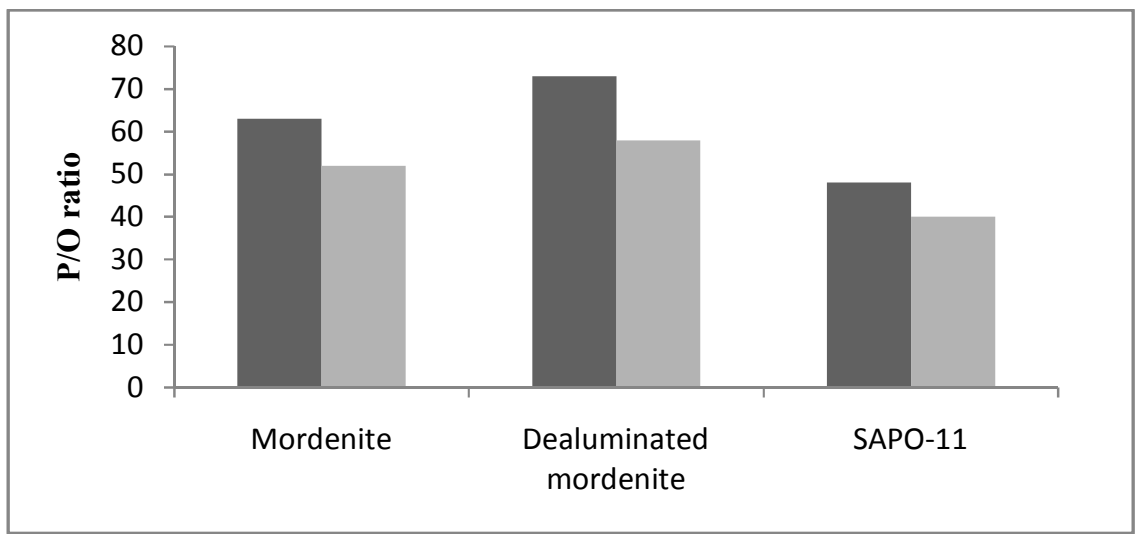

Figure 7. P/O ratio over 3 zeolite catalysts at $6 \mathrm{~h}$ and $12 \mathrm{~h}$ reaction time.

Bull. Chem. Soc. Ethiop. 2017, 31(2) 
The higher $\mathrm{P} / \mathrm{O}$ ratio over dealuminated mordenite catalyst is due to the higher diffusivity of $p$-xylene into the large pore of mordenite compared to the mordenite and medium pore of SAPO-11 (4 $\AA$ × $6.5 \AA)$. $p$-Xylene quickly diffusion into the dealuminated mordenite zeolite as soon it forms $[28,29]$.

Overall, the presented data here showed that our synthesized catalysts have good performance in comparison to the previous studies $[3,30]$.

\section{CONCLUSIONS}

In this study, we successfully synthesized a mordenite zeolite with high crystallinity. Dealumination of the zeolite with nitric acid treatment increased Si/Al ration, pore volume and surface area of the zeolite. The performances of prepared zeolites investigated in $m$-xylene isomerization reaction in a fixed bed reactor and compared them with the commercial SAPO-11 catalyst. The changes in the pore volume of mordenite significantly increased $m$-xylene conversion to branched products, which might be due to the enhanced diffusion of $p$-xylene molecules through the improved porous system of the dealuminated mordenite.

Based on the results which were obtained from this study the amounts of $p$-xylene which were produced and $\mathrm{P} / \mathrm{O}$ ratios over three catalysts were increased in the order of: modified mordenite $>$ mordenite $>$ SAPO-11. Para/ortho ratio significantly improved using dealuminated mordenite compared to mordenite without dealumination. $m$-Xylene conversion over SAPO-11 was higher than mordenite but was less than dealuminated mordenite.

Finally reviewing the results showed that the prepared mordenite and dealuminated mordenite are better catalysts than SAPO- 11 in $m$-xylene isomerization reaction in terms of the amount of $p$-xylene which was produced, $\mathrm{P} / \mathrm{O}$ ratio and xylene loss.

\section{REFERENCES}

1. Gonzalez, H.; Rodriguez, A.; Cedeno, L.; Ramirez, J. Isomerization of $\mathrm{C}_{8}$ aromatics over a $\mathrm{Pt} /$ mordenite catalyst. A statistical model. J. Ind. Eng. Chem. Res. 1996, 35, 3964-3972.

2. Sreedharan, V.; Bhatia, S. Vapour phase isomerization study of $m$-xylene over a nickel hydrogen mordenite catalyst. J. Chem. Eng. 1987, 36, 101-109.

3. Sen Sarma, P.-K.; Bhatia, S. Liquid phase xylene isomerization over nickel hydrogen mordenite catalyst, Zeolites 1987, 7, 511-516.

4. Ahmed, K.; Sameh, M.; Eman, A.; Sahar, M. Catalytic para-xylene maximization. V. Toluene methylation with methanol and disproportionation of toluene using Pt/ZSM-5 and Pt/mordenite catalysts. J. Chin. Chem. Soc. 2004, 51, 817-826.

5. Guisnet, M.; Gnep, N.S.; Morin S. Mechanisms of xylene isomerization over acidic solid catalysts. Micropor. Mesopor. Mat. 2000, 35-36, 47-59.

6. Sunday Fabiyi, F.A.; Adediran, G.O.; Olatunji, M.A. Application of copper catalysis of the oxidation of 2-hydrazino pyridine by hydrogen peroxide: A kinetic method of analysis. Bull. Chem. Soc. Ethiop. 2001, 15, 9-14.

7. Nawaz, Z.; Shu, Q.; Naveed, S.; Wei, F. Light alkane (mixed feed) selective dehydrogenation using bi-metallic zeolite supported catalyst. Bull. Chem. Soc. Ethiop. 2009, 23, 429-436.

8. Pramod, K.B.; Rao, M.S.; Gokhale, K.V.G.K. Synthesis of mordenite type zeolites. Ind. Eng. Chem. Prod. Res. Dev. 1978, 17, 223-227.

9. Mohamed, M.; Tarek, M.; Ibraheem, O.; Ibraheem, A. Synthesis of high silica mordenite nanocrystals using o-phenylenediamine template. Micropor. Mesopor. Mater. 2005, 84, 8496. 
10. Hisham, M.; Moustafa, E.; Ehab, A. Synthesis of mordenite zeolite in absence of organic template. Powder Technol. 2012, 23, 757-760.

11. Xianfeng, L.; Roel, P.; Jeroen, A. Synthesis and characterization of mesoporous mordenite. J. Catal. 2009, 262, 257-265.

12. Tsai, T.-C.; Liu, S.-B.; Wang, I. Disproportionation and transalkylation of alkylbenzenes over zeolite catalysts. Appl. Catal. A. 1999, 181, 355-398.

13. Maia, D.G.; Yolanda, C.; Pilar. S. Comparison of dealumination of zeolites beta, mordenite and ZSM- 5 by treatment with acid under microwave irradiation. Micropor. Mesopor. Mater. 2011, 144, 162-170.

14. Baerlocher, C.H.; McCusker, L.B.; Olson, D.H. Atlas of Zeolite Framework Types, 6th ed.; Elsevier: USA; 2007.

15. Barrer, R.M.; Makki, M.B. Molecular sieve sorbents from clinoptilolite. Can. J. Chem. 1964, 42, 1481-1487.

16. Me'ariadeau, P.; Ben Taarit, Y.A.; Thangaraj, J.; Almeida, L. G.; Naccache, C. Zeolite based catalysts for linear alkylbenzene production: Dehydrogenation of long chain alkanes and benzene alkylation. Catal. Today 1997, 38, 243-247.

17. Boveri, M.; Marquez-Alvarez, C.; Angel Laborde, M.; Sastre, E. steam and acid dealumination of mordenite characterization and influence on the catalytic performance in linear alkylbenzene synthesis. Catal. Today 2006, 114, 217-225.

18. Olken, M. M.; Garces, J. M.; Higgings, J. B.; Treacy M. M. J.; (Eds.), Proceedings of 9th International Zeolite Conference, Butterworth-Heinemann, Boston, MA, 1993, Montreal, Canada, 1992, p. 559.

19. Lee, G. J.; Garces, J. M.; Meima, G. R.; Van der Aalst, M. J. M.; US Patent NO. 32517, 1989.

20. Peng, G.; Xiaofeng, L.; Shang, Z.; Qinghu, X.; Tao, D. Quasi-solid state synthesis of EU-1 zeolite and its catalytic properties for the isomerization of $\mathrm{C}_{8}$ aromatics. J. Pet. Sci. Eng. 2012, 9, 544-550.

21. MarceIo, L.; Diego, I.; Nádia, R.C.; Fernandes, M.; Sibele, B.C. Synthesis of mordenite using kaolin as Si and Al source. Appl. Clay Sci. 2008, 41, 99-104.

22. Treacy, M.M.J.; Higgins, J.B. Collection of Simulated XRD Powder Patterns for Zeolites, 4th ed, Elsevier: Oxford; 2001.

23. Yi, W.; Yuichi, K.; Toshio, O.; Removal of low-concentration ammonia in water by ionexchange using Na-mordenite, Water Res. 2007, 41, 269-276.

24. Viswanadham, N.; Kumar, M.; Effect of dealumination severity on the pore size distribution of mordenite. MicroporMesopor Mat. 2006,92(1-3), 31-37.

25. Selvam, T.; Schwieger, W. Synthesis and Characterization of Mordenite (MOR) Zeolite Derived from a Layered Silicate, Na-Magadiite. Stud. Surf. Sci. Catal. 2002, 142, 407-414.

26. Ahmed, M.H.M.; Muraza, O.; Amer, A.M.A. Effect of synthesis parameters and ion exchange on crystallinity and morphology of EU-1 zeolite. J. Alloys Compd. 2014, 617, 408412.

27. Dodwell, G.W.; Denkewicz, R.P.; Sand, L.B. Crystallization of EU-1 and EU-2 in alkali and alkali-free systems. Zeolites 1985, 5, 153-157.

28. Guillon, E.; Sanchez E. US Patent No. 7,893,309 B2, 2011.

29. Liu, Y.; Yan, A.; Xu. Q. Acidity, diffusion and catalytic properties of the silicoaluminophosphate SAPO-11. Appl. Catal. A 1991, 67, 169-177.

30. Nasiru, M.T.; Sulaiman, Al.-K. Comparison studies of xylene isomerization and disproportionation reactions between SSZ-33, TNU-9, mordenite and ZSM-5 zeolite catalysts. Chem. Eng. J. 2011, 166, 348-357. 